\title{
The Lived Experiences of the Lombok Earthquake Survivors
}

\author{
Ahmad Mumtaz Tauba ${ }^{1}$, Suryani $^{2}$, Imas Rafiyah ${ }^{2}$ \\ ${ }^{I}$ Master Program in Nursing, Faculty of Nursing, Universitas Padjadjaran, Indonesia \\ ${ }^{2}$ Faculty of Nursing, Universitas Padjadjaran, Indonesia \\ Corresponding Author: Ahmad Mumtaz Tauba (tobatajama@gmail.com
}

Received: 15 August 2019

Revised: 17 April 2020

Accepted: 18 April 2020

\begin{abstract}
Background: The large-scale earthquake which had struck off Lombok, an island in West Nusa Tenggara, made the survivors faced poor conditions, difficulties, and lack of supplies. Besides physical losses, the survivors also experienced various psychological health disorders that significantly affected their psychological condition as well as life.

Purpose: This study was aimed at exploring and gaining deeper meaning from the lived experiences of the Lombok earthquake survivors.

Methods: This study used a qualitative method with a descriptive phenomenological approach to elucidate the phenomena from experiences. The participants were ten (10) survivors of the Lombok earthquake, who were determined by purposive sampling. Data were collected through in-depth interviews and analyzed using Colaizzi's method.

Results: The results showed six emerging themes, including (1) problems solving skills when disaster strikes, (2) surviving from the limitations and difficulties, (3) feeling accustomed to earthquake, (4) family is a key source of strength to continue life, (5) getting closer to God by doing religious prayers and actions to have peace of mind, and (6) learning from the disasters to become a better human being.

Conclusion: The lived experience of the Lombok earthquake survivors was a long journey where they survived and adapted the difficult situations, as later, they could turn the under-pressure conditions to chances for their personal development. Findings of this study provide insights for nurses to greatly contribute to solving post-disaster psychological issues by strengthening the survivors' religious aspects, trauma healing, play therapy, and peer-support group.
\end{abstract}

Keywords: Lived experience, Lombok earthquake, natural disaster, survivors

How to cite: Tauba, A. M., Suryani, \& Rafiyah, I. (2020). The lived experiences of the Lombok earthquake survivors. Nurse Media Journal of Nursing, 10(1), 22-35. doi:10.14710/nmjn.v10i1.24964

Permalink/DOI: https://doi.org/10.14710/nmjn.v10i1.24964

\section{BACKGROUND}

The context of this study is based on interviews with $\mathrm{Mr} . \mathrm{Z}$ as one of the earthquake survivors in Lombok, an island in West Nusa Tenggara, Indonesia. Mr. Z stated that besides causing physical damage and injuries, the earthquake disaster also caused survivors to experience psychological problems. Marthoenis, Yessi, Aichberger, and 
Schouler-Ocak (2016) stated that most survivors will experience serious psychological impacts and can last in the long term so that it affects their behavior in living their daily lives. Psychological disorders occurred among survivors include acute stress, posttraumatic stress, and depression related to trauma. According to Shenk, Mahon, Kalaw, Ramos, and Tufan (2010), trauma is the main psychological impact of a disaster.

Trauma is an emotional response to terrible events such as natural disasters. This happens immediately after the incident. If the trauma is not handled properly, it will result in acute stress disorder (ASD) and post-traumatic stress disorder (PTSD). Birmes et al. (2009) revealed that ASD occurred three days to one month after experiencing trauma, whereas PTSD occurred after one month experiencing the event of trauma. In the context of life experience to face and overcome difficult conditions after a disaster, a person who experiences it is named a survivor, not a victim. He/she struggles to survive and overcome problems despite the limitations and difficulties caused by the disaster (Suryani, Welch, \& Cox, 2013).

Several studies on natural disaster survivors have been conducted either in Indonesia or other countries. However, the earthquake disaster that occurred in Lombok has different characteristics from previous studies. This characteristic is a long period of disaster. A report from BMKG (Meteorological, Climatological, and Geophysical Agency) stated that in August 2018, there were five significant earthquakes in Lombok with earthquake strength above 6.3 to 7.0 SR. Over the next 20 days, 2.566 aftershocks have occurred (Meteorological, Climatological, and Geophysical Agency, 2019). Based on data collection through preliminary interviews, a year after the Lombok earthquake, participants and surrounding communities still felt several aftershocks. Supported by data from BMKG on July 18, 2019, that the earthquake again struck Lombok with a magnitude of 4.1 SR. On July 24, 2019, there was still an earthquake with a magnitude of 4.3 SR (Meteorological, Climatological, and Geophysical Agency, 2019). The earthquake results in differences in the psychological response of earthquake survivors in Lombok and other regions.

In Indonesia, several studies have been conducted on natural disaster survivors, including research on tsunami survivors in Aceh in 2004 and the earthquake in Yogyakarta in 2006. According to Sunarti (2007), in the case of the tsunami in Aceh and earthquake in Yogyakarta, mental disorders are one of the main post-disaster health problems besides physical health problems such as the tetanus outbreak. Different results were found in Lombok. Based on reports obtained from the medical records of a mental hospital in West Nusa Tenggara during a preliminary study, it was shown that the number of mental disorders in 2017 amounts to 20,554 people. At the end of 2018, the number of mental disorders was 20,711. This means that after the earthquake in Lombok, there was no significant increase in the number of mental patients.

Results of observations also show another phenomenon that not all survivors in Lombok experience severe psychological disorders after the disaster. Even some of them became volunteers who participated in helping other victims of disaster, such as rescuing victims trapped in the rubble of buildings, initiators of the relocation of refugee villages, and carrying out trauma healing for refugees. This condition can occur because the life 
experiences that disaster survivors have are different, subjective, and individual so that they produce different psychological responses to each individual in dealing with traumatic experiences. Subjective experiences mean how survivors live their daily lives in the limitations and pressures of life, the efforts made to survive, the symptoms they feel, their hopes, and the quality of life of survivors (Suryani, 2013; Bowers, Kreutzer, Cannon-Bowers, \& Lamb, 2017).

Research on natural disaster survivors is important because a person's survival process can be known through his life experience. The journey of survivors in the process of dealing with traumatic experiences can make an effective contribution to preventing and overcoming psychological problems compared to medical treatment (Allott, Liu, Proffitt, \& Killackey, 2011). Therefore, it is necessary to conduct in-depth research and explore the experiences of earthquake survivors in Lombok.

\section{PURPOSE}

This study was aimed at exploring and gaining deeper meaning from the lived experience of the Lombok earthquake survivors.

\section{METHODS}

\section{Design and participants}

This research is related to the experiences, perceptions, and feelings of individuals who became survivors of the earthquake disaster in Lombok. Therefore, researchers used a qualitative method with a descriptive phenomenological approach to describe and explain the phenomena from experiences (Creswell, \& Poth, 2012). There are two reasons why phenomenology is suitable for this research. First, this research deals with the lives of people who have encountered specific experiences such as becoming natural disaster survivors, and second, this phenomenon is firstly observed in Lombok. In phenomenology studies, a deeper understanding of philosophical assumptions is important to identify these assumptions (Suryani, Welch, \& Cox, 2016). This research explores the experiences of survivors who encountered the earthquake disaster in Lombok.

The participants in this study were ten survivors who directly experience the earthquake disaster in Lombok. The determination for the number of participants is based on the achievement of the level of data saturation.

\section{Research instrument and data collection}

In qualitative research, the researcher acts as a key instrument. The researcher conducts the collection, documentation, and interviewing the participants to obtain all the data that is desired by the researcher (Creswell, \& Creswell, 2017). The data in this study were collected using in-depth interview techniques in the form of open-ended questions from participants who met the inclusion criteria. The interview lasted for about 40 to 65 minutes. In the interview process, each participant provided different information despite having the same experiences. Therefore, the researchers investigated and learned the background of specific participants, and then asked questions naturally and spontaneously, using the language that was mostly understood by participants. The researchers gave participants the broadest opportunity to answer the questions raised. 
The researchers also tried to encourage participants to share their experiences honestly. In the final stage, the researcher evaluated the results of the interview then validated the data that required confirmation from the participants.

\section{Data analysis}

The data analysis used in this study was the Colaizzi method by validating the results of the final data to the participants. It means that what is written by the researcher is following the participant's intentions (Polit \& Beck, 2010). According to Suryani et al. (2016), the Colaizzi method is suitable for analyzing phenomena. The steps of data analysis are: (1) obtaining the essence of each interview transcript, (2) extracting important statements, (3) formulating the meaning of a significant statement regarding the research objectives, (4) organizing the meaning formulated into a collection of themes, (5) writing a complete description of the research phenomenon, (6) describing the basic structure of the research phenomenon, and (7) validating the results of existing transcripts to all participants. During the data analysis process, an important thing that the researchers did was bracketing. It means that the researchers focused on the statements that the participants expressed and tried to put aside understanding and prejudice about the phenomenon under study.

\section{Ethical consideration}

Participants who were willing to become research respondents were asked to fill out an informed consent sheet. The researchers respected the privacy and confidentiality of participant data, explored participant experiences in accordance with research ethics, and used language that could be understood by each participant. This research was reviewed and approved by the Health Research Ethics Committee of the Faculty of Medicine, Padjadjaran University, number 712/UN6.KEP/EC/2019.

\section{RESULTS}

The results of this study showed that the age of participants ranged from 19 to 92 years old. Six were males, and the other four were females. Participants had diverse religious, educational, and occupational backgrounds. All participants were survivors who had been refugees; seven of whom were volunteers who participated in helping other disaster victims.

The results of interviews with the participants found six essential themes, consisting of the ability to overcome problems in disaster situations, surviving in limitations and difficulties, feeling accustomed to earthquakes, the presence of a family as a strong source to continue life, getting closer to God by performing worship rituals, and taking wisdom from disaster to become a better human being. The themes are described separately to express the meaning of the participant's life experience. However, there are interrelations between each theme.

\section{Ability to overcome problems in a disaster situation}

In the first theme, participants revealed various efforts made to overcome every problem experienced during the earthquake disaster. The incident was expressed as a gripping experience causing stress, panic, and fear. In this condition, six out of 10 participants 
expressed they were trying to overcome feelings of stress, panic, and fear by being calm. The following was the expression of participant 4 :

“... Sad, we are so sad, we are lost, the mind wanders ... In that state, we try to calm down, but it is very difficult. After feeling calm, finally, the tense atmosphere diminished" (P4).

In addition to overcoming panic by being calm, there was a phenomenon in which laughter and joking become one of how participants dealt with psychological problems caused by disasters. Furthermore, for participant 7, joking and laughing was not only a way to overcome problems but rather a way to enjoy life during difficult conditions:

"... We made many jokes when we gathered, that what makes us happy, the mind is not only focused on the earthquake. Emotions, anxiety, and fatigue reduced. That is how we enjoy life when it is tough" (P7).

Different from other participants, participant 3 overcame panic, fear, and depression by trying to think positively:

"... Because when the situation is panic, nothing is easy, just open the door, it's hard to ask for forgiveness, even though we just have to check it, we try to control ourselves by thinking we will be safe, so we feel calmer" (P3).

\section{Survival in limitations and difficulties}

In this study, all participants expressed feeling that they were living in limitations and difficulties during the disaster. So, they made various efforts to survive. The following was the expression of participant 4:

"... We use whatever we found, especially at that time, the water was very difficult. Before help comes, we drink turbid water, and we surely survive" (P4).

During the conditions of limitations and difficulties, the majority of participants revealed that they found strength in togetherness. They together strengthened each other so they could survive. The following was an expression from participant 4 :

“... Equally advising each other, the bond of brotherhood in the refugee camp was tight. If someone seems to have problems, all immediately gathered. We are like returning to our childhood that togetherness is back again" (P4).

Furthermore, participants realized that they could not deal with disaster alone, as illustrated in the following expression of participant 1:

“... We cannot escape from our neighbors and family, because this disaster cannot be faced alone. Some families and neighbors help, where to ask for help and assistance" (P1). 
Apart from having to survive the limitations and difficulties caused by the disaster, most participants felt threatened by thieves and looters shortly after the earthquake shook. To preserve property, participants conducted social cooperation in the form of mobile patrols and security posts. The following was the expression of participant 6 :

"... When the dusk has begun to tense, like when fighting against the Dutch, at 5 p.m., the teenagers return to their respective posts to patrol, we must ensure that the tents of families and residents are safe, the atmosphere is like the 80s" (P6).

\section{Feeling accustomed to earthquakes}

Most of the participants in this study revealed that they felt accustomed to the earthquake. The change in reaction to the earthquake was expressed by participant 4 , as follows:

“... We cannot count it, ... because there must be an earthquake every 10-20 minutes, until now. However, the earthquake is big, but we tried to get used to it. At first, our feet felt shaking, but now we are getting used to it" (P4).

Based on the experiences expressed by the participants, earthquakes were previously perceived as tense cases, but afterward, they were considered as normal cases to produce a better psychological response. Participant 5 stated the following:

“... After that, aftershocks still came. I gradually got used to it. After the big earthquake, small quakes came. So I just stayed in the room not in a hurry, tired of running, even running could make us fall and get hurt" (P5).

\section{The presence of a family as a strong source to continue life}

On this theme, all participants revealed that the presence of the family was a source of strength to continue living. Specifically, the presence of the family was very beneficial for participants in living a life full of stresses and difficulties, both during and after disasters disaster. The following was the expression from participant 2:

"... Family is everything. The first that motivates us is the family, not others. So, don't leave your family." (P2).

Six out of 10 participants in this study lost their homes due to the earthquake disaster. For the six participants, the family was more meaningful than the house and property they owned, as expressed by participant 3:

"... For me family is everything, a family is more valuable than property" (P3).

Furthermore, the family was the main reason for most participants to survive and move on, as illustrated in the expression of participant 6 :

"... The thing that makes me conquer it all is family, why? ...because if I were alone, I would not be able to control myself. I would be frustrated. If I were frustrated, then who would strengthen them?" (P6). 


\section{Getting closer to God by performing worship rituals}

A total of four participants expressed gaining peace through worship rituals such as prayer, prayer, recitation, remembrance, and charity. There were also spiritual aspects that make participants feel calm in the form of resignation (submission to God), sincerity, and belief in destiny (faith), as illustrated by participant 2 :

"...Not as agitated as before, like when it first happened, now we feel calmer in anticipating things. Reciting, praying, doing dhikr, and then asking for forgiveness from God, sharing fortune if there is, giving alms." (P2).

Meanwhile, for participants 3, belief in destiny made him feel calmer in interpreting the occurrence of disasters. According to him, the natural disasters that occurred was provisions set by God. Participant 3 stated the following:

"Fostering a sense of calmness in the heart, that's for sure, surely feeling calmer if you believe in God's destiny" (P3).

After experiencing the earthquake disaster, almost all participants revealed that they were trying to increase worship to prepare for life in the afterlife, as expressed by participant 9:

“... Life is only temporary, bad or good house is only temporary. I want a good home in the afterlife by doing worship" (P9).

\section{Taking wisdom from disaster to become a better human being}

Almost all participants in this study consider that the earthquake was a warning from God that humans need to try to be better than before, as expressed by participant 2:

“... I consider this disaster as a warning to be more trustworthy and devoted to Allah" (P2).

Although believing in the disaster was a warning and reprimand due to any unpleased action, it did not make the participants feel punished or hated by God. On the contrary, for most participants, the condition of surviving a disaster was considered an opportunity to improve. The following was the expression of participant 7:

“... Yes, we are self-conscious; we must not judge people in this area as a sinner. If we feel ourselves are not good enough, then try to improve ourselves" (P7).

A slightly different statement was expressed by participant 9. According to him, after the disaster, everyone became equal; there were no rich and poor people, no luxurious homes, and ugly houses. Everything became equal. According to participant 9, there were things they could learn from the disaster. 
“... House. Before the disaster, some houses were ugly; others were large and luxurious. After the disaster, all the houses were flat. There were no longer the rich and the poor, all the same; the houses were equally flat." (P9).

\section{DISCUSSION}

In this study, each participant provided different information despite having the same experience. This condition can occur because the life experiences that disaster survivors have are subjective and individual so that they can produce different psychological responses to each individual in dealing with traumatic experiences (Suryani, 2013).

\section{Ability to overcome problems in a disaster situation}

The ability of survivors to overcome problems is influenced by various factors, including interpersonal relationships, internal and external resources that they have. According to Ponizovsky, Finkelstein, Poliakova, Mostovoy, Goldberger, and Rosca (2013), these factors affect the ability of individuals to deal with a problem. Most survivors in this study tried to overcome the panic experienced by being calm. According to participants, a calm attitude in stressful conditions when experiencing a disaster was very effective in reducing feelings of fear, depression, and panic so that it could save them from life-threatening conditions. It is in line with a study by Suryani (2013), which stated that the experience of survivors in facing and overcoming challenges every day is subjective. It means that individuals use all their strengths in their limitations as sources of strength. Survivors can find their way of overcoming problems.

Besides, some participants also made efforts to joke and laugh as a part of their sense of humor. According to Eysenck (2012), individuals with a good sense of humor can look at problems from a more positive perspective. It contributes to reducing anxiety and feelings of helplessness. However, in this study, a sense of humor is not only a way to overcome problems, but also a way to enjoy life during difficult conditions.

Another effort made by participants in overcoming their problems is by trying to think positively in stressful situations. Positive thinking is closely related to emotions. Survivors with positive thoughts are more likely to reduce stress (Phanichrat \& Townshend, 2010). The statement reinforces the findings of Mondal et al. (2013) that the survivor's ability to think positively will have an impact on the accuracy of making decisions, the ability to control emotions, and being calm.

\section{Survive in limitations and difficulties}

Individuals who experience psychological problems after a disaster have a chance to survive and overcome the problem. It is related to resilience that describes the ability of survivors to overcome and adapt to an adverse event in life. It describes the effort made by survivors to survive in a state of stress and deal with the traumatic experience they have (Suryani, 2013).

Based on the results of the study, participants gained the strength to survive in togetherness. This is following the results of a study by Oflaz, Hatipoğlu, and Aydin (2008), which revealed that post-disaster psychological problems could be overcome by 
improving social and interpersonal relationships, especially among fellow disaster victims. This study is also in line with Richardson, Cobham, McDermott, and Murray (2013), reporting that feeling the same fate as having experienced the same incident can strengthen self-confidence and alleviate feelings of distress. Besides, participants also revealed their efforts to survive the threat of thieves and looters shortly after the earthquake. This is a new phenomenon in Lombok and maybe in Indonesia because it is due to natural disasters. There are no previous research results related to natural disaster survivors regarding this theme. According to Goto, Wilson, Kahana, and Slane (2006), cases such as theft and looting caused by the condition of people who have difficulty getting food and drinks so that they decide to steal.

In this study, participants made efforts to survive through social cooperation such as patrolling, cooperation, and mutual care. This condition shows a positive social relationship with fellow disaster victims. Based on the results of a study by Yamamoto (2011) on earthquake survivors in Japan, it was reported that individuals with positive social relationships and social support from their communities tended to be more capable to effectively overcome the difficulties and pressures of life.

\section{Feeling accustomed to earthquakes}

Based on the results of the study, there was a phenomenon where most participants were able to overcome feelings of anxiety, panic, fear, and stress after feeling accustomed to the earthquake. This phenomenon caused by the earthquake that occurred in Lombok lasted continuously for a long time. Based on a review of various literature on natural disaster survivors in Indonesia and abroad, no research discusses the theme of feeling accustomed to earthquakes or other natural disasters.

The results of the study of Ma et al. (2011) for survivors in China found that postdisaster psychological problems such as trauma is still felt by survivors after three years of the earthquake disaster. Similarly, research by Shenk et al. (2010) in Peru showed that three years after the disaster, most of the survivors still survived in the refugee camp because they felt traumatized. From the results of the study, participants felt accustomed after 11 days to 2 months after the disaster. It was further revealed that the feeling of being accustomed to an earthquake is not an ability acquired through effort, but arouse due to difficult conditions that forced them to adjust.

Difficult conditions that occur in a long period can encourage individuals to try to find ways to reduce stress (Ponizovsky et al., 2013). Referring to the results of Yamamoto's study (2011), survivors have adapted to difficult situations characterized by reduced psychosocial impacts in the aftermath of a disaster. In line with this statement, Christia (2012), in her research, explained that survivors who have repeated similar experiences would know better how to act to get out of stressful conditions after a disaster.

The emergence of the theme of feeling accustomed to earthquakes is a new insight in this study as it is not reported in previous studies regarding the life experience of natural disaster survivors. This could be due to the experience of survivors in dealing and interpreting disasters as subjective to produce different psychological responses in each survivor (Suryani, 2013). 


\section{The presence of a family as a strong source to continue life}

Life after a disaster is a state of stress and difficulty for survivors. This condition made participants need tangible support from various sources to survive the difficulties caused by the disaster. All participants in this study revealed the amount of support and meaning of family presence. Participants became more eager to move on. This finding is supported by the research of Musa et al. (2014) related to the experience of tsunami survivors in Aceh that the presence of families is a source of strength and motivation needed in living life during and after a disaster.

Various literature studies are carried out to find out why certain survivors have stronger resilience than other individuals when facing difficulties. Studies by Warsini, Mills, West, and Usher (2016), and Levine, Laufer, Stein, Hamama-Raz, and Solomon (2009) have identified factors that strengthen survivor resilience, namely the existence of the family as a source of strength in facing and overcoming difficulties. The findings in this study are consistent with the results of previous studies. Participants revealed that the family is a source of strength to survive and move on.

Based on a study by Sharp (2010), survivors may not be able to overcome their problems and need the role of other people around them, especially their families. The importance of family presence is expressed by Shenk et al. (2010) in his study that survivors displaced by disasters tended to feel worthless because they did not have anything. The support of the family in the form of love and affection is very helpful in increasing their confidence. It means that family is the most valuable and meaningful for participants. Family presence is a source of strength and motivation in living a difficult life.

\section{Getting closer to God by performing worship rituals}

The findings of this study indicated that most participants tried to gain peace of mind by getting closer to God through rituals of worship such as prayer, dhikr, chanting, and giving alms. There are also spiritual aspects, namely trusting (surrender to God), sincerity by accepting the difficult conditions and having faith in destiny. Mohr et al. (2011) explains that spirituality is a means for soul recovery to increase self-confidence and relieve feelings of difficulty. Lukoff (2007) stated that spirituality is a part of soul recovery through worship rituals such as praying and reading scriptures. Survivors can gain peace, self-confidence, develop their self-worth as humans, and gain optimism in living life.

The results of a study by Piyasil et al. (2011) about tsunami survivors in Thailand found a strong influence of spiritual values such as acceptance of God's will and belief in destiny (faith) on the resilience of survivors. Spiritual values can be protective factors that strengthen the resilience of survivors, so they are safe from more severe psychological problems. Previous studies showed that protective factors in the form of spirituality could increase the resilience of survivors (Hayward, \& Krause, 2014; Uyun, \& Witruk, 2016). 


\section{Taking wisdom from disaster to become a better human being}

A phenomenon has meaning because someone experiences it and gives meaning to the experience (Suryani, 2013). After the disaster, most of the participants felt they had developed into stronger personalities through the experience and wisdom gained when experiencing life difficulties. The lessons learned include being better at dealing with stress, becoming more religious than before, trying to be a better human being, and finally feeling more grateful for what they have. Raj and Subramony (2008) revealed that the ability of survivors to take wisdom from an unpleasant event in life indicates success in carrying out the process of adaptation to adversity. The study also showed that the survivors had strong resilience. It supports a study by Irmansyah, Dharmono, Maramis, and Minas (2010), that survivors with strong resilience can develop ways of changing stressful situations into an opportunity to become a better personality.

Some participants believed that the disaster was a warning from God so that the wisdom could be gained in the form of efforts to improve themselves to become a better human being. The effort to take lessons from a disaster is motivated by the beliefs held by most of the participants in this study. In the perspective of being a Muslim, participants believe that there is always wisdom behind adversity. This is also reported by Musa et al. (2014) in a study related to tsunami survivors in Aceh, Indonesia. Survivors with high spirituality tend to take lessons from the difficulties experienced, especially after the tsunami disaster. By taking lessons from the conditions of difficulties caused by disasters, survivors gain peace and confidence in overcoming life's difficulties.

This study has its limitations. The participants in this study were the survivors who directly experienced the earthquake disaster in Lombok, and only a small number of survivors were involved in this study. As a result, the findings of this study cannot be generalized to the broader population. However, the findings of this study have the potential to fill a "blind spot" in knowledge about the lived experience of earthquake disaster survivors.

\section{CONCLUSION}

In this study, four new insights found, namely the ability to deal with stress through the effort to joke and laugh, feeling accustomed to earthquakes, surviving the threat of thieves and looters, and taking lessons from disaster to become a better human being. In conclusion, the life experience of a natural disaster survivor is a long journey where survivors try to survive and adapt to difficult conditions. Therefore, they can turn a stressful state into an opportunity to develop themselves into better personalities than before. The results of this study are expected to be a reference for nurses in making greater contributions to overcome psychological problems after a disaster by enhancing the spiritual aspects of victims, trauma healing, playing therapy, and peer support groups.

\section{ACKNOWLEDGEMENT}

The authors would like to thank all participants and other parties who have supported and facilitated the study. 


\section{CONFLICT OF INTEREST}

The authors declare no conflict of interest.

\section{REFERENCES}

Allott, K., Liu, P., Proffitt, T. M., \& Killackey, E. (2011). Cognition at illness onset as a predictor of later functional outcome in early psychosis: Systematic review and methodological critique. Schizophrenia Research, 125(2-3), 221-235.

Birmes, P., Raynaud, J. P., Daubisse, L., Brunet, A., Arbus, C., Klein, R., ... \& Schmitt, L. (2009). Children's enduring PTSD symptoms are related to their family's adaptability and cohesion. Community Mental Health Journal, 45(4), 290-299.

Bowers, C., Kreutzer, C., Cannon-Bowers, J., \& Lamb, J. (2017). Team resilience as a second-order emergent state: A theoretical model and research directions. Frontiers in Psychology, 8, 1360.

Christia, M. (2012). Experiences of people affected Merapi eruption in 2010: A qualitative study conducted in Krinjing village Indonesia (Master's thesis). Faculty of Medicine, University of Oslo.

Creswell, J. W. \& Poth, C. N. (2012). Qualitative inquiry and research design: Choosing among five approaches. London: SAGE Publications.

Creswell, J. W., \& Creswell, J. D. (2017). Research design: Qualitative, quantitative, and mixed methods approaches. London: Sage publications.

Eysenck, M. W. (2012). Simply psychology. Hove, UK: Psychology Press.

Goto, T., Wilson, J. P., Kahana, B., \& Slane, S. (2006). The Miyake Island volcano disaster in Japan: Loss, uncertainty, and relocation as predictors of PTSD and depression. Journal of Applied Social Psychology, 36(8), 2001-2026.

Hayward, R. D. \& Krause, N. (2014). Religion, mental health and well-being: Social aspects. In V. Saroglou (Ed.), Religion, Personality, and Social Behavior (pp. 255280). New York: Psychology Press.

Irmansyah, I., Dharmono, S., Maramis, A., \& Minas, H. (2010). Determinants of psychological morbidity in survivors of the earthquake and tsunami in Aceh and Nias. International Journal of Mental Health Systems, 4(1), 8.

Levine, S. Z., Laufer, A., Stein, E., Hamama-Raz, Y., \& Solomon, Z. (2009). Examining the relationship between resilience and posttraumatic growth. Journal of Traumatic Stress, 22(4), 282-286.

Lukoff, D. (2007). Spirituality in the recovery from persistent mental disorders. Southern Medical Journal-Birmingham Alabama, 100(6), 642-646.

Ma, X., Liu, X., Hu, X., Qiu, C., Wang, Y., Huang, Y., ... \& Li, T. (2011). Risk indicators for post-traumatic stress disorder in adolescents exposed to the 5.12 Wenchuan earthquake in China. Psychiatry Research, 189(3), 385-391.

Marthoenis, M., Yessi, S., Aichberger, M. C., \& Schouler-Ocak, M. (2016). Mental health in Aceh-Indonesia: A decade after the devastating tsunami 2004. Asian journal of psychiatry, 19, 59-65.

Meteorological, Climatological, and Geophysical Agency. (2019). Gempabumi tektonik M 5,5 mengguncang Kabupaten Sumbawa, tidak berpotensi tsunami [The M 5.5 tectonic earthquake shook Sumbawa Regency, no potential for tsunami]. Retrieved from https://www.bmkg.go.id/berita/?p=gempabumi-tektonik-m-55-mengguncangkabupaten-sumbawa-tidak-berpotensi-tsunami\&lang=ID\&tag=nusa-tenggara-barat 
Mohr, S., Perroud, N., Gillieron, C., Brandt, P. Y., Rieben, I., Borras, L., \& Huguelet, P. (2011). Spirituality and religiousness as predictive factors of outcome in schizophrenia and schizo-affective disorders. Psychiatry research, 186(2-3), 177182.

Mondal, R., Sarkar, S., Banerjee, I., Hazra, A., Majumder, D., Sabui, T., ... \& Pan, P. (2013). Acute stress-related psychological impact in children following devastating natural disaster, the Sikkim earthquake (2011), India. Journal of Neurosciences in Rural Practice, 4(Suppl 1), S19-S23.

Musa, R., Draman, S., Jeffrey, S., Jeffrey, I., Abdullah, N., Halim, N. A. M., ... \& Midin, M. (2014). Post tsunami psychological impact among survivors in Aceh and West Sumatra, Indonesia. Comprehensive Psychiatry, 55, S13-S16.

Oflaz, F., Hatipoğlu, S., \& Aydin, H. (2008). Effectiveness of psychoeducation intervention on post-traumatic stress disorder and coping styles of earthquake survivors. Journal of Clinical Nursing, 17(5), 677-687.

Piyasil, V., Ketumarn, P., Sitdhiraksa, N., Pithayaratsathien, N., Pariwatcharakul, P., Lerthattasilp, T., ... \& Wanlieng, T. (2011). Tsunami Disaster in Thailand: A 5Year Follow-Up. Journal of the Medical Association of Thailand, 94(Supp13), 138144.

Phanichrat, T., \& Townshend, J. M. (2010). Coping strategies used by survivors of childhood sexual abuse on the journey to recovery. Journal of Child Sexual Abuse, 19(1), 62-78.

Polit, D. F., \& Beck, C. T. (2010). Generalization in quantitative and qualitative research: Myths and strategies. International Journal of Nursing Studies, 47(11), 1451-1458.

Ponizovsky, A. M., Finkelstein, I., Poliakova, I., Mostovoy, D., Goldberger, N., \& Rosca, P. (2013). Interpersonal distances, coping strategies and psychopathology in patients with depression and schizophrenia. World Journal of Psychiatry, 3(3), 7484.

Raj, S. B., \& Subramony, S. (2008). Impact of tsunami on the mental health of victims. Journal of the Indian Academy of Applied Psychology, 34, 132-140.

Richardson, M., Cobham, V., McDermott, B., \& Murray, J. (2013). Youth mental illness and the family: Parents' loss and grief. Journal of Child and Family Studies, 22(5), 719-736.

Sharp, I. A. (2010). Immigration as a "theologizing Experience": Spiritual well-being as a moderating factor in migratory grief and acculturation (Doctoral dissertation). Loyola University Chicago.

Shenk, D., Mahon, J., Kalaw, K. J., Ramos, B., \& Tufan, I. (2010). Understanding the disaster experience of older adults by gender: The experience of survivors of the 2007 earthquake in Peru. Health Care for Women International, 31(11), 965-980.

Sunarti, E. (2007). Evaluasi penanggulangan bencana di Indonesia (Lesson learned 2006-2007). Bogor: Lembaga Penelitian dan Pengabdian kepada Masyarakat Institut Pertanian Bogor.

Suryani, S. (2013). Salat and dhikr to dispel voices: The experience of Indonesian Muslim with chronic mental illness. Malaysian Journal of Psychiatry, 22(1).

Suryani, S., Welch, A., \& Cox, L. (2013). The phenomena of auditory hallucination as described by Indonesian people living with Schizophrenia. Archives of psychiatric nursing, 27(6), 312-318. 
Suryani, S., Welch, A., \& Cox, L. (2016). The application of Colaizi's method in conducting research across two languages. Malaysian Journal of Psychiatry, 25(1), 19-28.

Uyun, Q., \& Witruk, E. (2016, November). The effectiveness of sabr (patience) and salat (prayer) in reducing psychopathological symptoms after the 2010 Merapi eruption in the region of Yogyakarta, Indonesia. In Proceedings of the 5th International Congress on Interdisciplinary Behavior and Social Science (ICIBSoS 2016) (pp. 5-6).

Warsini, S., Mills, J., West, C., \& Usher, K. (2016). Living through a volcanic eruption: Understanding the experience of survivors as a phenomenological existential phenomenon. International Journal of Mental Health Nursing, 25(3), 206-213.

Yamamoto, A. (2011). Experiences of the great East Japan earthquake march 2011. International nursing review, 58(3), 332-334. 